\title{
NEOLIBERALISMO E FLEXIBILIZAÇÃO DA LEGISLAÇÃO TRABALHISTA NO BRASIL E NA FRANÇA
}

\author{
Neoliberalism and the flexibilization of labor law in Brazil and France
}

\begin{abstract}
Maurício Azevedo de Araújo
doutorando em Direito pela Universidade Federal do Paraná. Professor dos cursos de direito da UFBA e da UNEB. E-mail: araujo_mauricio@hotmail.com
\end{abstract}

\section{Renata Queiroz Dutra} Doutora em Direito pela Universidade de Brasília. Professora da Faculdade de Direito da UFBA. Email: renataqdutra@gmail.com

Selma Cristina Silva de Jesus

Pós-doutorado em sociologia pela Université Paris Nanterre. Professora da Faculdade de educação e PPGCS da UFBA. E-mail: selmacsj@gmail.com

Informações do artigo Recebido em 18/12/2017 Aceito em 27/12/2017

\begin{abstract}
Resumo
No contexto mundializado de ascensão de uma "racionalidade neoliberal" e desmonte dos direitos e dos mecanismos de proteção social, este artigo procura demonstrar como as reformas trabalhistas no Brasil e na França estão em conformidade com esta racionalidade, que visa à regulação das relações de trabalho sob o paradigma do direito privado e sua lógica negocial. O artigo é composto de três partes principais. Na primeira parte, será feita uma reflexão sobre o neoliberalismo e a precarização social do trabalho no Brasil e na França. Em seguida, serão analisadas as mudanças recentes na legislação trabalhista brasileira, notadamente no que concerne à aprovação do projeto de lei que libera a terceirização de atividades-fim no país (Lei $n^{\circ}$ 13.429/2017), bem como a Lei no 13.467/2017 (Reforma trabalhista). E por fim, no caso francês, o foco de análise recairá sobre as duas últimas reformas trabalhistas implementadas em 2016 e 2017, dando ênfase ao debate do negociado sobre o legislado, da flexibilidade das dispensas e dos limites da jornada de trabalho.

Palavras-chave: Neoliberalismo, Precarização, Direito do Trabalho, Reformas, Brasil, França.
\end{abstract}

\section{Introdução}

Este artigo versa sobre as recentes mudanças nos marcos regulatórios das relações do trabalho no Brasil e na França, tendo como pano de fundo o debate sobre o neoliberalismo e a precarização social do trabalho. A literatura na área da sociologia do trabalho demonstra que a partir dos anos 1970 há o estabelecimento de um novo padrão de desenvolvimento, que foi designado por Harvey (1992) de acumulação flexível. Este padrão deu origem a um novo modo de trabalho e de vida, baseado em dois processos simultâneos: tem-se, de um lado, a flexibilização das estruturas produtivas e salariais e de outra parte, o desmantelamento da proteção social.

No âmbito do trabalho, a simultaneidade dos processos mencionados acima resultou na precarização social do trabalho - que tem como dimensões fundamentais a condenação da legislação trabalhista, a orquestração de uma crise do direito do trabalho (DRUCK, 2013; DRUCK e FRANCO, 2007) e o desmonte da rede institucional que se prestava a assegurar a sua efetividade. 
É no contexto desta suposta crise do direito do trabalho que se busca analisar as recentes mudanças na legislação trabalhista no Brasil e na França, dando ênfase ao debate do negociado sobre o legislado. O artigo é composto por três partes principais. Na primeira parte, será feita uma reflexão sobre o neoliberalismo e a precarização social do trabalho no Brasil e na França, com intuito de identificar as semelhanças, mas também as especificidades de tais fenômenos em cada um dos países.

Em seguida, serão analisadas as mudanças recentes na legislação trabalhista brasileira, notadamente no que concerne à aprovação do projeto de lei que libera a terceirização de atividades-fim no país (Lei no 13.429/2017), bem como a Lei no 13.467/2017 (Reforma trabalhista), que condensa a proposta do negociado sobre o legislado, aperfeiçoa a nova Lei sobre terceirizações, além de rever toda a CLT, introduzindo regras de flexibilização nos contratos, nas jornadas, nas dispensas e no próprio acesso dos trabalhadores à Justiça.

E na terceira seção do artigo, analisamos as duas últimas reformas trabalhistas francesas implementadas em 2016 e 2017, com investidas significativas sobre a prevalência da negociação sobre a legislação, flexibilidade das dispensas e os limites de jornada.

Por fim, registramos que este artigo resulta de uma ampla pesquisa bibliográfica e documental realizadas nos dois países. Deste modo, analisamos a bibliografia especializada sobre neoliberalismo e as reformas trabalhistas no Brasil e na França. Nesta análise, atenção especial foi dada aos estudos que versavam sobre os reflexos destas reformas sobre a dinâmica do trabalho e do emprego nos dois países.

Em seguida, realizamos uma pesquisa documental que teve como foco a análise das novas leis trabalhistas dos dois países. No caso francês, analisamos a Lei n. 2016-1088 de 8 de agosto de 2016 (conhecida como Lei El Khomri, ministra do trabalho na presidência de François Hollande ) e as Ordonnances ${ }^{1}$ do atual presidente francês, Emmanuel Macron. E no caso brasileiro, as principais fontes consultadas na pesquisa documental foram o projeto de

\footnotetext{
A ordonnance é instrumento similar à Medida Provisória no Brasil. Trata-se de uma medida adotada pelo governo que tem efeitos imediatos e pode adquirir força de lei, quando aprovada pelo congresso. No caso francês, o governo tem que solicitar ao Parlamento autorização para utilizar uma ordonnance visando implementar seu programa. Esta autorização é concedida por meio da votação de uma lei de habilitação. $O$ processo de utilização das ordonnances envolve seis etapas, a saber: 1) O Parlamento autoriza ao Governo utilizar as ordonnances; 2) As ordonnances são utilizadas pelo Conselho de Ministro; 3) Depois, elas são assinadas pelo Presidente da República; 4) Em seguida, promulgam-se as ordonnances, que passam a ter vigência imediata; 5) Ao mesmo tempo, o Governo encaminha ao Parlamento um projeto de ratificação das ordonnances; 6) O parlamento pode aprovar o projeto de ratificação e neste caso as ordonnances ganham força de lei, assim como o Parlamento pode rejeitar as ordonnances, neste caso, estas caducam.
} 
lei que libera a terceirização de atividades-fim no país (Lei nº 13.429/2017), a Lei n $13.467 / 2017$ (Reforma trabalhista) e a medida provisória n 808, de novembro de 2017.

\section{Neoliberalismo e precarização do trabalho}

Com o fordismo, o capitalismo se estruturou predominantemente através do trabalho na sua forma assalariada, levando a constituição da sociedade salarial nos países centrais ${ }^{2}$, por meio da qual os trabalhadores recebiam não apenas uma renda, mas também reconhecimento e proteção social. Sob tal perspectiva, o trabalho assalariado passou a ser concebido como a forma predominante de inserção na estrutura social (CASTEL, 1998). Contudo, nos últimos 40 anos, este modelo de regulação da sociedade capitalista entrou em crise, ocasionando um profundo processo de mudanças que reorganizou a vida social em todas as suas dimensões. Sob novas bases, foram criadas as condições objetivas e subjetivas para reação do capital, que se expressou por meio de três movimentos: neoliberalismo, reestruturação produtiva e mundialização (DRUCK, 1996). Tais movimentos inauguraram um novo padrão de desenvolvimento capitalista, designado por Harvey (1992) de acumulação flexível.

A acumulação flexível levou a constituição de um novo modo de trabalho e de vida pautado na simultaneidade da flexibilização das estruturas produtivas e salariais e no desmantelamento da proteção social (BARRETO, 2005; BOURDIEU, 1998; CASTEL, 1998, DRUCK e FRANCO, 2007), resultando na precarização social do trabalho - definida por Druck (2013, p. 373) como "processo econômico, social e político que se tornou hegemônico e central na atual dinâmica do capitalismo". Trata-se, conforme a referida autora, de uma estratégia de dominação do capital largamente utilizada nos países centrais e periféricos do sistema capitalista no contexto da globalização e das políticas neoliberais, cujos resultados dentro e fora do mundo do trabalho se diferenciam em função das especificidades nacionais e regionais.

2 Conforme Druck (1999, p.59 e 6o), o fordismo sofre variações conforme as especificidades nacionais e regionais. No caso brasileiro, por exemplo, não se verificou a constituição de uma sociedade salarial tal como observado nos países desenvolvidos. Isto porque "[...] não ocorreu no Brasil o processo de integração de amplas massas ao mercado de trabalho e de consumo. Assim como não se constituiu Estado de bemestar social, a exemplo dos países centrais. Aqui, inicialmente, os direitos do trabalho consagrados na CLT (Consolidação das Leis do Trabalho), ficaram restritos aos trabalhadores urbanos. 
A despeito das especificidades nacionais que diferenciam a França e o Brasil (particularmente em relação aos distintos patamares de cidadania e direitos sociais conquistados nos dois países), observa-se que a institucionalização da precarização do trabalho ocorreu por meio das alterações na legislação do trabalho e da previdência, das novas formas de atuação de instituições públicas e pela fragilização dos sindicatos. Em outros termos, nos casos brasileiro e francês, a precarização social se processou por meio de uma dupla institucionalidade: de um lado, a precarização econômica, que institucionalizou a flexibilização do trabalho; e, de outra parte, pela precarização do sistema de proteção ou Previdência Social (APPAY, 1997 apud HIRATA e PRÉTECEILLE, 2002).

É neste contexto de institucionalização da precarização do trabalho que se estabeleceu uma "crise do direito do trabalho" e, por consequência, as reformas trabalhistas na França e no Brasil. Esta suposta crise do direito do trabalho está, portanto, umbilicalmente relacionada à hegemonia do neoliberalismo, que se contrapôs ao estado de bem-estar social e redefiniu o tipo de intervenção do estado. Na era da acumulação flexível, o Estado criou novas regulamentações e uma ordenação jurídica que privilegia o direito privado como condição de desenvolvimento da lógica neoliberal (DARDOT e LAVAL, 2016). É nesta direção que aponta Galvão (2003) ao afirmar que a desregulamentação dos mercados de trabalho e financeiro se processa através de novas regulamentações.

Ao propor uma analise das reformas no contexto neoliberal, este artigo parte da sugestão de Dardot e Laval de compreender o neoliberalismo não apenas como uma ideologia ou uma política econômica, mas como uma racionalidade ${ }^{3}$ que estrutura tanto as práticas governamentais como dos governados. Assim, para os referidos autores, "o neoliberalismo pode ser definido como um conjunto de discursos, práticas e dispositivos que determinam um novo modo de governo sobre os homens segundo o princípio universal da concorrência" (DARDOT e LAVAL, 2016, p. 17).

Tendo na concorrência seu elemento operacional e na lógica da empresa o modelo de subjetivação dos indivíduos, o neoliberalismo enquanto racionalidade promove o deslocamento das concepções tradicionais de cidadania e trabalhadores para um modelo que tem no empreendedorismo, no "homem-empresa" e sua gestão individual da vida e dos riscos

3 Para compreensão da ideia de racionalidade política, os autores franceses partem da definição de Foucault nos seus cursos de 1978/19, intitulados "o nascimento da biopolítica", que, em torno da discussão sobre o conceito de governamentalidade, vai analisar os tipos de racionalidades e procedimentos utilizados pela administração do Estado sobre as condutas dos indivíduos (DARDOT e LAVAL, 2016; FOUCAULT, 2008). 
a norma de conduta dos sujeitos. Desta forma, valores e práticas como solidariedade, ação coletiva e direitos sociais são deslegitimados em função de um individualismo concorrencial, efeito desta racionalidade que Dardot e Laval (2016, p. 328) apontam:

[...] a racionalidade neoliberal produz o sujeito que necessita ordenando os meios de governá-lo para que ele se conduza realmente como uma entidade em competição e, por isso, deve maximizar seus resultados, expondo-se ao risco e assumindo inteira responsabilidade por eventuais fracassos.

Outro elemento desta racionalidade neoliberal, diferente do consenso geral, diz respeito à necessidade de um Estado forte que garanta, ao mesmo tempo, o processo de desregulamentação dos direitos sociais e a proteção e promoção do direito privado. As reformas da previdência e do direito do trabalho em curso em diversos países são exemplos significativos desta nova política de Estado, que consiste na desconstrução de um sistema de proteção social e no estímulo de normas legais e de conduta que incitam a concorrência e transferem para os indivíduos a responsabilidade pela vida e seus riscos.

Neste contexto mundializado de ascensão de uma "racionalidade neoliberal" e desmonte dos direitos e mecanismos de proteção social, este artigo procura demonstrar como as reformas trabalhistas no Brasil e na França estão em conformidade com esta racionalidade, que visa à regulação das relações de trabalho sob o paradigma do direito privado e sua lógica negocial.

\section{A reforma trabalhista no Brasil}

A legislação trabalhista brasileira, embora tenha por principal marco normativo a CLT, que data de 1943, sofreu ao longo do tempo diversas modificações pontuais, seja por meio da edição de instrumentos legais específicos (exemplo disso é a criação do FTGS e o consequente fim da estabilidade decenal no emprego, originariamente prevista na CLT), seja por meio de alterações no próprio texto da CLT, que, dos 625 artigos que versam sobre direito material do trabalho, apenas 255 conservam a redação original de 1943 (SOUTO MAIOR, 2016).

A maior parte das alterações e inovações verificadas, entretanto, revelam o incurso do projeto neoliberal em relação à proteção trabalhista no Brasil, tendo prevalecido medidas de flexibilização da legislação posta, notadamente na década de 1990, em que, seja pela via legislativa, seja pela via jurisprudencial (Súmulas do Tribunal Superior do Trabalho), aspectos 
importantes da regulação trabalhista foram alterados (como exemplo, permissividade da terceirização de atividade-meio, banco de horas e outros sistemas de compensação de jornada, contratos de trabalho a tempo parcial e por prazo determinado, entre outros aspectos).

De forma contra hegemônica a esse cenário, a promulgação da Constituição Federal de 1988 reconfigurou o cenário normativo do Direito do Trabalho no país, não só por ampliar o rol de direitos previstos na legislação infraconstitucional, mas também por reorientar a interpretação desses direitos a partir de princípios constitucionais de valorização da pessoa humana e do próprio trabalho. Isso revela a tensão constitutiva da ordem constitucional, sobretudo no campo social, ao abarcar a convivência conflituosa de um projeto constitucional extremamente progressista do ponto de vista democrático e social justamente com o período de avanço do pensamento neoliberal nas esferas política, econômica e social do país.

Após o golpe parlamentar de 2016 e a reconfiguração de forças políticas conservadoras no Congresso Nacional e no Poder Executivo, tal tensão se acentua, implicando a condução de uma série de medidas que atentam contra a arquitetura constitucional de proteção ao trabalho delineada pela Constituição de 1988. Merecem ser destacadas nesse contexto as reformas trabalhista e previdenciária, além de medidas como cortes orçamentários na Justiça do Trabalho, congelamento dos gastos públicos por 20 anos (PEC n 241, atual Emenda Constitucional n 95/2016), cortes em programas sociais e políticas públicas de distribuição de renda, a exemplo do programa "bolsa família".

Em relação à reforma trabalhista, as medidas, de início, se assentavam em dois pilares principais: a liberação da terceirização de atividades-fim, originalmente centrada no PLC no 30/2015 (anterior PL nº 4330), e a prevalência do negociado sobre o legislado, sustentada nos Projetos de Lei nº 4193/2012 e 4962/2016.

Ajunçãodessas duas propostasjáteria por resultado uma desconfiguração da legislação trabalhista pátria, eis que, de um lado, com a liberação total da terceirização, descaracterizase o contrato bilateral de trabalho, base sobre a qual se constroem e asseguram todos os demais direitos trabalhistas na CLT e sem a qual eles se tornam rarefeitos (DELGADO; AMORIM, 2014); e, de outro, com a prevalência do negociado sobre o legislado, se finda a imperatividade do patamar mínimo dos direitos trabalhistas, eis que esses passariam a ser negociados pelos sindicatos em prejuízo do trabalhador, numa conjuntura de crise econômica 
e fragilização sindical que dá ampla margem à negociação in pejus, como observa o DIEESE (2016).

Todavia, o PLC no $30^{4}$, projeto de lei da terceirização, que já vinha sendo pauta prioritária do empresariado brasileiro e que, em certa medida, fora objeto de debate com as Centrais Sindicais, sobretudo durante a fase de tramitação na Comissão de Direitos Humanos do Senado Federal, foi subitamente deixado de lado em favor do PL nº 4302/1998, que havia sido aprovado no Senado Federal ao final do Governo Fernando Henrique Cardoso, em dezembro de 2000, pendendo somente de deliberação pela Câmara dos Deputados. Tal aprovação aconteceu em março de 2017, em regime de urgência, com votação da maioria dos Deputados e sanção pelo Presidente da República ainda naquele mês, o que deu origem à Lei $n^{\circ} 13 \cdot 429 / 2017$.

Por meio dessa legislação, que alterou a Lei n 6.019/74 (Lei do trabalho temporário), o contrato de trabalho temporário, que é uma figura correspondente a uma das modalidades de contratação intermediada ou terceirizada, se torna ainda mais precário. Se antes havia autorização para a realização de contratação temporária por até três meses; a partir dessa lei, passa a ser possível a contratação temporária por 180 dias, prorrogáveis por mais 90, ou seja, por um total de 270 dias.

A consequência disso é que o contrato de natureza temporária, que permite ao trabalhador uma inserção precária no mercado de trabalho (sem perspectiva de permanência e, assim, sem um mínimo de segurança social, sem possibilidade de estabelecer compromissos financeiros futuros, sem inserção na categoria profissional, etc.) seja banalizado, substituindo assim a criação de postos de trabalho protegidos e de prazo indeterminado, em franco prejuízo ao princípio da continuidade da relação de emprego. A lei também modifica o rol de direitos do trabalhador temporário: assegura a ele o salário equivalente ao dos empregados da empresa tomadora que desempenham a mesma função, mas suprime a menção ao patamar salarial e aos direitos da categoria sindical correspondente, o que cumpre um dos mais deletérios objetivos da terceirização, que é apartar o trabalhador de sua categoria sindical original.

De outro lado, a Lei n $13.429 / 2017$ inseriu na Lei do trabalho temporário uma disciplina geral sobre a terceirização (arts. $4^{\circ}-\mathrm{A}$ a $5^{\circ}-\mathrm{B}$ ), de forma muito pouco técnica e genérica, que menciona a terceirização de atividades "específicas" e prevê a responsabilidade subsidiária do

4 Originalmente PL n 4330, após a aprovação na Câmara dos Deputados em abril de 2015, passou a ser denominado PLC no 30 no Senado. 
tomador de serviços. É aqui que se abre a perspectiva para a generalização da terceirização de forma preocupante, cuja amplitude (inclusive terceirização de atividade-fim) foi reafirmada com a aprovação da Reforma Trabalhista5.

Dando por vencida a batalha da terceirização, o Congresso Nacional e o Governo, numa manobra de aceleração e ampliação do conteúdo da reforma trabalhista, aprovou a Lei $n^{\circ}$ 13.467/2017, num prazo de tramitação extremamente reduzido e sem amadurecimento da discussão com a sociedade, à revelia do que exigem as Convenções nº $144 \mathrm{e} 154$ da OIT $^{6}$, que requerem, respectivamente, consulta tripartite e consulta às organizações de trabalhadores para a implementação de revisões amplas da legislação trabalhista no âmbito dos países membros. A aceleração do processo legislativo, desenvolvido sob o regime de urgência e a ausência de debate com a sociedade dão o tom da racionalidade pós-democrática de que tratam Dardot e Laval (2016).

A Lei n $13.467 / 2017$, além de tornar expresso o conteúdo de permissividade quanto à terceirização de atividade-fim, cuja possibilidade a Lei nº 13.429/2017 abrira, e de sintetizar o conjunto de alterações legislativas necessárias à prevalência do negociado sobre o legislado,

\section{se propõe a revisar quase todo o texto da CLT.}

Para além da prevalência da negociação coletiva sobre o legislado, a reforma que o projeto concretiza na CLT, numa perspectiva liberalizante, assenta-se na ideia de autonomia individual do trabalhador para negociar com o empregador sobre as condições do seu contrato de trabalho, descolando-se da premissa de assimetria das relações de trabalho e de hipossuficiência do trabalhador em face do empregador, ou seja, do próprio princípio da proteção que funda o Direito do Trabalho. Conforme demonstraremos a seguir, essa perspectiva liberalizante também orienta as duas últimas reformas trabalhistas na França.

Nesse intuito, confere ampla validade a acordos celebrados individualmente entre empregado e empregador sobre a jornada de trabalho, inclusive para instituir regimes

\footnotetext{
5 Importante firmar que, mesmo no marco da vigência da Lei n $13.467 / 2017$, além das necessárias ponderações sobre a constitucionalidade da norma, deverá ser observado o crivo dos arts. $2^{\circ}$ e $3^{\circ}$ da CLT, que definem os elementos da relação de emprego (pessoalidade, onerosidade, subordinação jurídica e não-eventualidade) e que, se presentes, podem invalidar a contratação terceirizada, mesmo diante da genérica autorização contida nos arts. $4^{\circ}-\mathrm{A}$ a $5^{\circ}-\mathrm{B}$ da Lei no 6019/74. Não sobeja destacar que a terceirização tem revelado ser um mecanismo de gestão indissociável da presença da subordinação jurídica, em algum grau, por parte do empregado em relação ao tomador de serviços (CAVALCANTE; FILGUEIRAS, 2015).

6 Nesse sentido, o Enunciado n 1 da ll Jornada de Direito Material e Processual do Trabalho, realizada em Brasília nos dias 9 e 10 de outubro de 2017 e organizada pela ANAMATRA - Associação Nacional dos Magistrados do Trabalho. Disponível em: http://www.jornadanacional.com.br/listagem-enunciados-aprovados-vis1.asp Acesso em 29/11/2017, 21h21min.
} 
de compensação agressivos, como o regime de banco de horas e até mesmo o regime de compensação $12 \times 367$, assim como para reduzir intervalos para repouso e alimentação dentro da jornada de trabalho, que passam a deixar de ser tratados como matéria de saúde e segurança dos trabalhadores.

Também são validadas, independentemente de intervenção sindical ou judicial, tratativas diretas do empregado com o empregador para estabelecer como modalidade de vinculação o trabalho autônomo (em detrimento do vínculo de emprego), a forma de extinção do contrato de trabalho, que agora passa a poder ser terminado por acordo entre as partes, com pagamento de indenização reduzida à metade, até a situação extrema dos empregados que recebem o dobro do teto da Previdência Social ${ }^{8}$, que poderão "optar" por resolver seus conflitos com o empregador mediante arbitragem, renunciando à possibilidade de levar suas demandas à Justiça do Trabalho (art. 507-A).

Corolário de tal perspectiva liberal de validação das negociações entre empregado e empregador é a restrição da atuação da Justiça do Trabalho, no sentido de invalidar acordos ou condições desfavoráveis aos empregados. Inclusive, o texto da reforma, em diversos pontos, nega entendimentos favoráveis aos trabalhadores consolidados pela Justiça do Trabalho, infirmando-os por meio de disposições expressas, que retiraram do Poder Judiciário Trabalhista a possibilidade de interpretar a CLT naquele sentido9 .

A Justiça do Trabalho passa a ter sua atuação restrita em relação à declaração de invalidade dos acordos realizados entre empregado e empregador, em relação à declaração de invalidade das normas coletivas firmadas pelo sindicato, bem como em relação à sua liberdade para arbitrar indenizações por danos morais em casos de ofensas morais aos trabalhadores, de discriminação ou acidentes de trabalho ${ }^{10}$ : esses valores passam a ser tabulados pela

7 Relevante registrar que, por meio da Medida Provisória n 808/2017, publicada em 14/11/2017, a pactuação do regime $12 \times 36$, à exceção do setor de saúde, foi restringida à negociação coletiva.

8 Valor que em janeiro de 2017 foi fixado em $\mathrm{R} \$ 5 \cdot 531,31$.

9 Apenas a título de exemplo, são entendimentos jurisprudenciais expressamente revertidos pela reforma: a incompatibilidade do acordo de compensação de jornada com a prestação habitual de horas extraordinárias, a inexistência da prescrição intercorrente no processo do trabalho, o direito ao pagamento do período integral do intervalo parcialmente suprimido pelo empregador, a vedação da aposição de propagandas de outras empresas no fardamento dos empregados, a admissibilidade de equiparação salarial em cadeia, o direito à incorporação da gratificação de função de confiança ocupada pelo empregado por mais de dez anos, o direito à existência de prévia negociação coletiva para a realização de dispensas coletivas, a ultratividade das normas coletivas, entre outros.

10 A reforma também contempla expressamente a possibilidade de os trabalhadores serem condenados ao pagamento de indenizações por danos morais às empresas, em casos de lesão à sua imagem. 
legislação, com previsão de indenizações relativamente reduzidas e proporcionais ao valor dos benefícios previdenciários máximos pagos pelo INSS ${ }^{11}$.

Outro vértice da reforma consiste em desonerar o empregador de responsabilidade, seja dificultando procedimentos como o reconhecimento do grupo econômico empresarial ou a desconsideração da personalidade jurídica do empregador em casos de fraude, seja isentando os sócios de responsabilidades pelas dívidas trabalhistas a partir do prazo de dois anos da sua retirada da sociedade.

Espécies contratuais precárias ou desprotegidas também foram criadas: ampliam-se as possibilidades de pactuação do contrato de trabalho por tempo parcial e cria-se a figura do contrato de trabalho intermitente, cuja principal característica consiste em atribuir ao empregado o ônus da ausência de demanda produtiva do empregador, situação em que ele deixa de ser remunerado, contrariando disposição elementar da CLT que previa que o tempo à disposição do empregador, ainda que sem prestação de serviços, seria remunerado, eis que é ele quem assume os riscos da atividade econômica.

De outro lado, por meio da Medida Provisória n 808/2017, a reforma trabalhista evidenciou o seu desdobramento previdenciário, ao colocar para os trabalhadores contratados de forma intermitente o ônus de completar a contribuição previdenciária, sempre que não seja atingido, por meio do recolhimento incidente sobre sua remuneração, o valor correspondente ao do salário mínimo, sob pena de perder a condição de segurado da Previdência Social. Não apenas se chancela forma de contratação precária, como também se assume deliberadamente a exclusão dos trabalhadores assim contratados do sistema previdenciário, uma vez que é óbvio, diante do contexto de crise econômica e da baixa remuneração que tendencialmente será percebida pelos contratados de forma intermitente, que a "opção" do trabalhador será pelo não recolhimento. Fica evidenciado também o contrassenso entre as medidas governamentais, que ampara o discurso em defesa da reforma previdenciária em um suposto rombo e em um suposto déficit de recolhimentos ao INSS, mas que desenvolve a reforma trabalhista por meio da instalação de uma precariedade incompatível com a manutenção do recolhimento das contribuições dos trabalhadores formais.

\footnotetext{
11 Relevante registrar que, por meio da Medida Provisória no 808/2017, publicada em 14/11/2017, o tabelamento das indenizações por danos morais na Justiça do Trabalho passou a adotar como critério o limite máximo dos benefícios do Regime Geral de Previdência Social, eis que o texto original da reforma previa a tabulação das indenizações de modo proporcional ao salário dos empregados, numa disparidade de quantificação dos sujeitos e das lesões por eles suportadas que foi altamente criticada.
} 
O sindicalismo também é alcançado pela Reforma Trabalhista, que, a pretexto de consolidar o valor da liberdade sindical, retira a principal fonte de financiamento sindical, tornando facultativo e condicionado a expressa opção do empregado o pagamento da contribuição sindical, assegurada na Constituição, sem oferecer possibilidade alternativa de financiamento, nem ao menos a curto prazo $^{12}$. Também regulamenta a figura dos representantes dos trabalhadores no local de trabalho (prevista no art. 11 da Constituição Federal), o fazendo por meio da comissão de representação ${ }^{13}$ dos trabalhadores na empresa, sem nenhum diálogo ou participação das entidades sindicais, numa franca perspectiva de fragmentação da representação dos trabalhadores, em detrimento de uma perspectiva construtiva de aproximação do local de trabalho.

Por fim, consolida-se a prevalência do negociado sobre o legislado, acentuandose que a negociação sindical pode abrir mão dos direitos, exceto aqueles assegurados expressamente na Constituição, e que tais acordos prevalecerão ainda que não ofereçam contrapartida expressa aos trabalhadores, sem que o Poder Judiciário possa declarar sua invalidade em razão do conteúdo prejudicial.

A nova legislação ataca também o princípio da norma favorável, princípio basilar do Direito do Trabalho, ao afirmar que os acordos coletivos (celebrados no âmbito de cada empresa) sempre prevalecerão sobre as convenções coletivas (celebradas para todas as empresas na base territorial), recuando na previsão original da CLT que assegurava a prevalência da norma mais favorável ao trabalhador (art. 620).

Do ponto de vista do acesso à Justiça do Trabalho e do processo judicial trabalhista, alteraçõesimportantessãoinseridasno sentido de validaracordos celebrados extrajudicialmente entre empregado e empregador (o que desconsiderada a especial vulnerabilidade do trabalhador em face daquele que lhe subordina e remunera), onerar o trabalhador com custos do processo (honorários advocatícios e periciais) e endurecer o tratamento contra condutas

\footnotetext{
12 Embora a medida responda a uma crítica à ausência de liberdade sindical negativa plena no sistema brasileiro, à revelia do que propugna a Convenção no 87 da OIT (LOURENÇO, 2011), é interessante observar como o encaminhamento dessa pauta decorre de uma agenda dos empregadores, e não dos trabalhadores e seus sindicatos, e em que não são pensadas alternativas aos impactos da medida, como forma de garantir o fortalecimento das entidades sindicais.

13 Tais representantes, embora agraciados com a garantia provisória do empregado, tem sua garantia excetuada quanto a um rol de dispensas mais amplo que o do dirigente sindical, visto que podem ser dispensados por motivo técnico, econômico ou disciplinar, ao passo que o dirigente sindical só perde o emprego em caso de cometimento de falta grave. Ressalte-se que, por meio da MP nº 808/2017, foi firmado que tal comissão não possuiria a prerrogativa de realização negociações coletivas para criação de normas.
} 
processuais desleais ou omissões do trabalhador em relação aos ritos processuais, elementos que podem gerar inibição em relação ao exercício do direito de ação.

A primeira sentença proferida no Brasil após a entrada em vigor da reforma trabalhista, aplicando imediatamente as normas processuais inerentes à reforma, não apenas julgou improcedentes os pedidos formulados pelo trabalhador, como condenou o trabalhador ao pagamento de honorários advocatícios e multa por litigância de má-fé, de modo que, ao reivindicar direitos, o trabalhador adquiriu uma "dívida" de $\mathrm{R} \$ 8.500,00^{14}$. O efeito inibidor dessa decisão e do próprio conteúdo da nova lei sobre a reivindicação judicial de direitos por parte dos trabalhadores é manifesto.

Assim como no Brasil, no caso francês, as reformas trabalhistas de 2016 e 2017 (principalmente) tiveram como eixo central o estabelecimento da prevalência da negociação coletiva sobre a legislação, conforme demonstraremos a seguir.

\section{A reforma trabalhista na França}

De acordo com Eydoux e Fretel (2016), dos anos 1980 até 2015, a França realizou diversas reformas do código do trabalho, que foram justificadas como necessárias para a recuperação do emprego. Assim como no caso brasileiro, as iniciativas institucionais tiveram por objetivo flexibilizar a legislação trabalhista, especialmente no que tange à contratação da mão-de-obra e à jornada de trabalho.

Dentre as inovações legislativas neste campo, as referidas autoras destacam: i) Lei "Auroux 1982", que estabeleceu a possibilidade de negociação por empresa da jornada de trabalho; ii) a Lei de 12 de novembro de 1996, que introduziu o dispositivo de negociação atípica, possibilitando o estabelecimento de acordos assinados na ausência de delegados sindicais; iii) Lei 2004-391 de 04 de maio de 2004, que estabelece a possibilidade de derrogação de um acordo por ramo, exceto aqueles que versam sobre quatros matérias definidas por lei: salário mínimo, financiamento da formação profissional e proteção social complementar; iv) Lei 2015-990 de 6 de agosto de 2015 (também chamada de Lei Macron), que autorizou a extensão do trabalho aos domingos, alterou o limite de tempo para caracterização do

\footnotetext{
${ }_{14}$ Disponível em: https://g1.globo.com/bahia/noticia/no-1-dia-de-vigencia-da-reforma-trabalhista-juiz-nabahia-condena-funcionario-a-pagar-r-85-mil-por-suposta-conduta-de-ma-fe.ghtml Acesso em 29/11/2017, $21 \mathrm{~h} 25 \mathrm{~min}$.
} 
trabalho noturno, mudou as regras de indenização em caso de demissão, dentre outras medidas. (Eydoux e Fretel, 2016).

Acrescentamos a esta lista apresentada pelas as autoras, as inovações legislativas mais recentes resultantes da reforma trabalhista de 2016 (do presidente François Hollande, conhecida como Lei El Khomri) e 2017 (do atual presidente Emmanuel Macron). Neste artigo, face à impossibilidade de analisar a totalidade das reformas do código do trabalho francês, o foco recairá sobre as mudanças promovidas pelas reformas trabalhistas de 2016 e 2017 em três aspectos das relações de trabalho: jornada de trabalho, flexibilidade das dispensas/ demissões e negociação coletiva.

Preliminarmente, é necessário destacar que as recentes reformas trabalhistas da França se enquadram em um conjunto de medidas de austeridades recomendas aos países da Zona do Euro pela Troika (Banco Central Europeu, Comissão Europeia e Fundo Monetário Internacional) como resposta à crise de 2008. Conforme Schömann (2015), embora alguns países tenham adotado tais medidas antes mesmo da crise de $2008^{15}$, a partir da crise a Comissão Europeia estabeleceu a "modernização" da legislação trabalhista dos países membros como medida prioritária, pois, na visão da referida Comissão, a retomada do crescimento de maneira durável, à elevação do nível de emprego e a redução da pobreza dependiam da flexibilização da legislação do trabalho. Dentre os países da União Europeia, a França foi um dos últimos a adotar a reforma do código de trabalho nos termos propostos pela Troika.

O projeto de Lei El Khomri tem sua origem relacionada a dois relatórios, quais sejam: o relatório Combrexelle ${ }^{16}$ de setembro de 2015 e o relatório Badinter de janeiro de $2016^{17}$. O primeiro relatório encaminhado ao Manuel Valls - primeiro ministro socialista de François Hollande - preconizava a necessidade de refundação do direito do trabalho visando aumentar sua eficácia e o campo da negociação coletiva nas relações de trabalho. O segundo relatório redigido por um comitê presidido por Robert Badinter - também defendia uma ampla reforma do código do trabalho visando sua simplificação.

15 A Alemanha realizou a reforma da legislação do trabalho em 2003, por exemplo.

16 O relatório recebeu o nome do seu autor, qual seja: Jean-Denis Combrexelle e encontra-se disponível em: http:// www.strategie.gouv.fr/sites/strategie.gouv.fr/files/atoms/files/fs_rapport_missionjdc_08092015.pdf .

${ }_{17}$ Para maior aprofundamento, consultar o relatório que encontra-se disponível em: https://www.humanite. $\mathrm{fr} /$ sites/default/files/conclusions-de-la-mission-de-robert-badinter-sur-les-principes-essentiels-du-droit-dutravail-.pdf . 
Registra-se que o segundo relatório retoma as idéias defendidas por Badinter em um livro publicado em 2015, em co-autoria Antonio Lyon-Caen. Nesta publicação, os autores argumentam que o código de trabalho francês era extremamente complexo e necessitava ser reformulado com intuito de oferecer aos empregadores e trabalhadores modelos de contratos informatizados, claros e de fácil compreensão, tal como aborda Espina (2016). Assim, os referidos juristas propuseram que o código do trabalho francês fosse organizado em três níveis de direito, quais sejam: 1) Princípios fundamentais do direito do trabalho que deveriam ser respeitados por todos, tais como: garantia dos direitos fundamentais dentro das empresas, respeito à dignidade da pessoa, etc. 2) direitos que poderiam ser objeto de negociação coletiva por ramo ou por empresa; 3) definição das disposições aplicáveis em casos da não existência de acordos. (ESPINA, 2016; WILLEMEZ, 2017).

Baseado nos relatórios Combrexelle e Badinter, em 17 de fevereiro de 2016, o projeto de lei do trabalho é publicado e defendido pela ministra do Trabalho, Emprego, da Formação Social e do Dialogo Social, Myriam El Khomri (WILLEMEZ, 2017). Segundo Willemez (2017), após a publicação do projeto, assistiu-se a uma onda gigante de protestos e greves organizados pelo movimento sindical e estudantes. De outra parte, a entidade Movimento das Empresas da França (MEDEF), principal associação patronal da França, que vinha desde 1999 produzindo documentos e pressionado governos a realizar uma reforma do código de trabalho, com intuito de estabelecer a prevalência da negociação, deu amplo apoio à reforma proposta pelo governo socialista de François Hollande.

Em função da magnitude da reação dos trabalhadores e dos estudantes, uma nova versão do projeto foi apresentada em abril de $2016^{18}$, na qual se retirou alguns artigos do projeto original. Este recuo por parte do Governo não foi suficiente para neutralizar as resistências ao projeto, que continuaram crescendo por meio da realização dos protestos tradicionais e greves semanais organizados principalmente pela Confederação Gera do Trabalho (CGT) e Força Obreira (FO), bem como dos atos promovidos pelo movimento "nuit debout"19.

A lei do trabalho (El Komri) também encontrou resistências no Congresso, inclusive entre os deputados e senadores do partido socialista. Por conta disto, o primeiro ministro

\footnotetext{
${ }_{18}$ As principais alterações da nova versão em relação ao projeto original dizem respeito ao alcance da prevalência da negociação sobre a legislação.

19 O nuit debout é um movimento que consistiu na ocupação de praças públicas na França (principalmente, em Paris) para protestar contra a reforma trabalhista proposta pelo Governo de Hollande.
} 
Manuel Valls faz uso do artigo 49 da Constituição, que permite evitar o voto parlamentar ao invocar a responsabilidade do governo. Desse modo, em agosto de 2016, a lei 20161088 relativa ao trabalho, a modernização do diálogo social e a segurança das trajetórias profissionais é promulgada.

De acordo com Willemez (2017), durante a campanha eleitoral para presidência da república, Emmanuel Macron apresentou em seu programa de governo as diretrizes de uma nova reforma do código de trabalho na França, cujo epicentro era ampliar o espaço da negociação por empresa. Findada a eleição, em agosto de 2017, o então presidente Macron prioriza a reforma do código do trabalho e inova em relação ao governo anterior: ao invés de apresentar um projeto de lei ao parlamento, Macron decidiu fazer a reforma por meio de Ordonnances (um instrumento similar a Medida Provisória no Brasil).

Logo após o anúncio da utilização de cinco ordonnances para realização da reforma trabalhista, teve início uma série de protestos e greves, tal como analisa Willemez (2017). Todavia, a despeito da reação, seguindo o rito legal, em 22 de setembro de 2017, as ordonnances foram assinadas pelo presidente Macron. E em 28 de novembro de 2017, as ordonnances de Macron foram aprovadas pelo parlamento francês, ganhando força de lei.

Conforme Willemez (2017), a reforma trabalhista de Macron reforçou e ampliou as possibilidades de uso dos dispositivos presentes na lei El khomri, principalmente no que diz respeito à ampliação das possibilidades do negociado prevalecer sobre o legislado. Destacamos que no caso da reforma de 2016, a prevalência da negociação sobre a legislação ficou restrita à jornada de trabalho. Esta foi uma das principais críticas de Macron à reforma El Khomri. O atual presidente da França defendia que era preciso ir mais longe e ampliar o espaço da negociação (inclusive, instituindo a negociação sem intermediação do sindicato no caso das pequenas empresas). Com efeito, a reforma trabalhista de 2017 estabeleceu em vários domínios a prevalência do acordo de empresa e/ou de ramo (ou setor) sobre a lei, conforme abordaremos adiante.

A lei El Khomri estabeleceu a possibilidade de através de um acordo de empresa se ampliar a jornada de trabalho semanal. Registramos que na França, a jornada legal de trabalho é de 35 horas em todos os setores da atividade econômica, o que passa disto deve ser considerado horas suplementares. Levando em conta as horas suplementares, a Lei El Khomri (no seu artigo 3121-35) define que o tempo máximo da jornada semanal é de 48 horas e em casos excepcionais pode chegar a 6o horas semanais (neste último caso é necessária 
a autorização da inspeção do trabalho). O artigo L. 3121-36 define que quando a jornada semanal for calculada em um período de 12 semanas consecutivas, o tempo desta não pode ultrapassar em média 44 horas por semana ou 46 horas/semana quando previsto em acordo por empresa ou convenção coletiva. Chama atenção o fato de que as horas suplementares podem ser negociadas via um acordo de empresa, antes este procedimento só poderia ser feito por meio do acordo de ramo (ou setor de atividade).

Ainda sobre as horas suplementares (ou extras), a lei El Khomri (2016) definiu que a lei prevê um aumento de $25 \%$ nas 8 primeiras horas e 50\% depois deste período $(L$ 312122). Contudo, existe a possibilidade de derrogar esta regra mediante acordo por empresa ou convenção coletiva, desde que respeitado o piso de $10 \%$ de acréscimo à hora extra trabalhada. Segundo Arfi-ElKaïm (2016), os acordos de empresa, em geral, são menos favoráveis para os trabalhadores do que os acordos coletivos de ramo.

Se no caso da Lei El Khomri, a primazia do acordo de empresa ou acordo coletivo de ramo se restringiu à questão do tempo do trabalho, as ordonnances ampliam esta possibilidade para outros temas, conforme mencionado anteriormente. Sobre esta questão, destacamos o fato das ordonnances estabelecerem que por meio do acordo coletivo (de ramo ou setor de atividade) um contrato temporário pode ter até cinco anos. Definiu, também, que a instituição de um contrato de tempo indeterminado (CDI) e o período de experiência podem ser negociados através de acordo coletivo de ramo (ou setor de atividade). As ordonnances instituíram que os benefícios e prêmios (tais como: antiguidade, licenças, $13^{\circ}$, saída para aposentadoria, etc.) serão objeto de negociação por acordo de empresa.

Sobre este aspecto, ressaltamos as críticas feitas por juristas e acadêmicos de que as reformas trabalhistas de 2016 e de 2017 (principalmente) fazem uma completa inversão da hierarquia das normas, já que no passado um acordo coletivo (seja ele de ramo ou de empresa) deveria garantir no mínimo o que está previsto na lei. Ou seja, um acordo coletivo não podia ser menos favorável para o trabalhador do que a lei. Ficava, portanto, resguardo o princípio da norma mais favorável. Após as referidas reformas, um acordo de empresa pode prevalecer sobre o acordo coletivo de ramo e a lei, mesmo que este acordo de empresa seja menos favorável ao trabalhador.

A reforma trabalhista de Macron estabeleceu também a possibilidade de negociação direta com os trabalhadores, sem a presença de delegados sindicais, em empresas com até 11 funcionários (artigo 2232-21 do Código do trabalho) para todos os temas passiveis 
de negociação (tais como: remuneração, prêmios, igualdade profissional entre homens e mulheres, etc.). Este tipo de negociação deve ser feito por meio de referendo (chamado de referendo de empresa) e para ser validada a proposta patronal deve obter a maioria de $2 / 3$ dos votos. Este modo de negociação também é possível no caso das empresas com 11 a 20 trabalhadores que não tenham Comitê Social e Econômico (CSE) ${ }^{20}$ ou delegado sindical, conforme o artigo 2232-23 do Código do trabalho francês.

Conforme o artigo 2232-23-1, no caso das empresas de 10 a menos de 50 trabalhadores, na ausência de delegado sindical ou do conselho de empresa, os acordos de empresa podem ser negociados de duas maneiras: i) por um ou mais funcionários eleitos por um ou mais sindicatos representativos no ramo; ii) um ou mais membros do Comitê Social e Econômico (CSE). Para serem validados, estes acordos devem ser acordos devem ser concluídos com um ou mais membros do referido comitê ou então devem assinados pelos representantes que obtiveram mais votos nas últimas eleições profissionais.

O referendo de empresa foi duramente criticado por diversos autores (MORIN, 2017; WILLEMEZ, 2017). Segundo Morin (2017), os dispositivos que instituem a possibilidade de negociação direita com os trabalhadores sem a intermediação dos sindicatos resultam da perversão da noção de acordo coletivo e do sentido de participação presentes no preâmbulo da Constituição francesa e na Convenção 98 da OIT (da qual a França é signatária). Nas palavras da autora:

Segundo a alínea 8 do preâmbulo da Constituição, todo assalariado participa por intermédio de seus delegados da determinação coletiva das condições de trabalho. Para negociar coletivamente, é necessário delegados (eleitos ou sindicais). (MORIN, 2017, p. 591).

Ainda segundo a mesma autora, este mesmo sentido de negociação coletiva está presente na Convenção 98 da OIT. Deste modo, na referida Convenção, a negociação coletiva prevê a existência de um lado de um empregador (ou um grupo de empregadores) e de outro, uma ou várias entidades representativas dos trabalhadores. A negociação direta entre empregador e empregados além de ignorar as organizações sindicais existentes, institui uma espécie de negociação unilateral por meio da qual a proposta patronal dificilmente será

\footnotetext{
20 O Comitê Social e Econômico (CSE) foi instituído pelas ordonnances e visa substituir todas as instituições representativas eleitas pelos trabalhadores de uma empresa. Deste modo, até janeiro de 2020, o CSE deve substituir as seguintes instâncias existentes atualmente numa empresa com pelo menos 11 empregados: o delegado de pessoal (DP), o comitê de empresa (CE) e o comitê de higiene, segurança e condições de trabalho (CHSCT).
} 
rejeitada pelos trabalhadores (agora mais fragilizados, já que devem manifestar diretamente sobre a proposta por meio do voto, sem intermédio dos sindicatos).

Conforme Willemez (2017), as mudanças em nome da ampliação do dialogo social resultam de um radical "processo de desestatização do direito do trabalho" (p. 190). Em nosso ver, este processo está fundamentado ampliação da lógica do direito privado como condição de desenvolvimento da "razão neoliberal", resultando na desconstrução do estatuto do assalariado e a tentativa de estabelecimento do trabalhador-empreendedor. Sob tal enfoque, o trabalhador-empreendedor deve ter assegurado no ambiente de trabalho apenas um conjunto de direitos individuais fundamentais básicos e os demais direitos devem resultar do processo de negociação com o empresário. Não é sem razão que o capítulo inicial da Lei El Khomri estabelece uma série de direitos individuais fundamentais, tais como: respeito à dignidade da pessoa, garantia de não discriminação em função do credo religioso, da condição de gênero, etc.

Em relação à ruptura do contrato de trabalho, as duas últimas reformas trabalhistas ampliam de forma considerável as possibilidades de demissão por motivo econômico. Deste modo, por meio da Lei El Khomri ficou estabelecido que uma empresa - em caso de dificuldade econômica (comprovada pela diminuição dos pedidos e dos números dos seus negócios em relação ao ano anterior) - pode demitir seus funcionários. A lei prevê, também, que no caso de empresas com menos de onze trabalhadores, uma queda em relação ao último semestre (e não ano) é o suficiente para que a empresa possa utilizar o dispositivo da demissão por motivo econômico. A lei El Khomri autoriza, ainda, a demissão por motivo econômico em caso de mudanças organizacionais necessárias para garantir a competitividade das empresas.

No tocante às demissões por motivos econômicos, a reforma conduzida pelo atual presidente, Emmanuel Macron, vai mais longe no sentido de garantir as empresas maior liberdade/flexibilidade para dispensa dos trabalhadores, uma vez que autorizam que a assinatura de um acordo por empresa pode instituir um plano de demissão voluntária, também chamado de ruptura convencional coletiva. Institui, ainda, a possibilidade de demissão em casos de recusa por parte do trabalhador da modificação do seu contrato de trabalho.

No que concerne à demissão por justa causa, as mudanças introduzidas pelas ordonnances são ainda mais radicais, conforme avalia Willemez (2017). Primeiramente, fica estabelecido um teto para as sanções pecuniárias impostas pela Justiça em caso de não comprovação da causa da demissão (ou seja, caso a demissão seja considerada abusiva pela 
Justiça). Institui-se, também que o recurso à Justiça contra demissão abusiva foi limitado em um ano (anteriormente eram de dois anos). E por fim, o empregador não é mais obrigado a comprovar os motivos da demissão, conforme previa o código de trabalho antes da reforma de 2017. Em síntese, neste campo, amplia-se consideravelmente a possibilidade do empregador de ajustar o quadro de funcionários em função da maior ou menor demanda por produção.

\section{Considerações Finais}

Inseridas num contexto geral de medidas neoliberais, as reformas trabalhistas no Brasil e na França pautam-se numa suposta imperatividade do mercado, que justificaria o sacrifício dos direitos fundamentais trabalhistas. Assentam-se na falsa premissa de que o barateamento dos custos trabalhistas e a consequente precarização das relações de trabalho geraria mais empregos ${ }^{21}$.

Num momento de crise econômica nos dois países, as medidas flexibilizadoras e negociais implicam na retirada de direitos, historicamente conquistados, pelas organizações sindicais, que tendem a se fragilizar ainda mais, no caso brasileiro isso poderá ocorrer em função da fragmentação das categorias pela terceirização, da perda imediata de sua fonte de financiamento e da criação de instâncias de representação alternativas aos sindicatos e na França, pelo estabelecimento de negociação sem participação dos sindicatos nas pequenas empresas e em alguns casos em empresas com até 50 empregados.

As reformas trabalhistas no Brasil e na França tiveram como eixo central o estabelecimento do negociado sobre o legislado e, conforme demonstramos, esse fato gerou um debate sobre a inversão da hierarquia das normas, uma vez que no passado a negociação coletiva deveria garantir no mínimo o que estava previsto na lei. Após as referidas reformas, um acordo no âmbito de uma empresa pode prevalecer sobre uma convenção coletiva (acordo de ramo/categoria profissional) e sobre a lei, mesmo que este acordo de empresa seja menos favorável ao trabalhador.

Desta forma, as reformas trabalhistas são indicadoras da nova política de Estado que de um lado promove a desconstrução de um sistema de proteção social e de outra parte, estimula a instituição de normas legais e de conduta que incentivam a concorrência e transfere para os trabalhadores os riscos inerentes ao trabalho. Como observam Dardot e Laval:

\footnotetext{
${ }^{21}$ Estudos da OIT infirmam diretamente essa premissa (OIT, 2015).
} 
A corrosão progressiva dos direitos ligados ao status de trabalhador, a insegurança instalada pouco a pouco em todos os assalariados pelas "novas formas de emprego" precárias, provisórias e temporárias, as facilidades cada vez maiores para demitir e a diminuição do poder de compra até o empobrecimento de frações inteiras das classes populares são elementos que produziram um aumento considerável do grau de dependência dos trabalhadores em relação aos empregadores. Foi esse contexto de medo social que facilitou a implementação da neogestão nas empresas. Nesse sentido a "naturalização" do risco no discurso neoliberal e a exposição cada vez mais direta dos assalariados às flutuações do mercado, pela diminuição das proteções e solidariedades coletivas, são apenas duas faces da mesma moeda (DARDOT; LAVAL, 2016, p. 329).

Importante notar que a implementação da chamada "Reforma trabalhista" no Brasil não se apresenta como processo perfeito e acabado, uma vez que a sua interpretação e mediação necessariamente passarão pelo crivo da atuação jurisdicional ${ }^{22}$ e das lutas sociais. Desse modo, no caso brasileiro, verifica-se a existência de divergência de entendimentos entre magistrados a respeito da interpretação e do próprio marco temporal da aplicação da norma, revelando que a normatização, ao revés do que prometido, produziu caos e insegurança jurídica ${ }^{23}$. Por outro lado, a despeito da fragilidade da condução do movimento sindical brasileiro em relação ao processo de tramitação da reforma, a sua entrada em vigor tem gerado reações espontâneas entre os trabalhadores, marcadas por perspectivas de resistência ${ }^{24}$.

A atuação do movimento sindical, ressalvadas as chamadas de greve geral nos dias 28 de abril e 30 de junho de 2017, que não obtiveram a adesão massiva dos trabalhadores (notadamenteasegundagreve, em que oinvestimento das instituições sindicaisfoimaistímido) tampouco foram capazes de intimidar as representações burguesas hoje predominantes no

22 Nesse sentido, a realização, nos dias 9 e 10 de outubro de 2017, da II Jornada de Direito Material e Processual do Trabalho, promovida pela Associação Nacional dos Magistrados Trabalhistas -ANAMATRA, no sentido de discutir teses sobretudo quanto à constitucionalidade da Reforma Trabalhista (Lei n 13.467/2017).

23 Notícias divergentes pululam na mídia a respeito da aplicação da reforma trabalhista: enquanto uma juíza do TRT de São Paulo extinguiu em um dia mais de 70 processos, aplicando retroativamente a parte processual da reforma trabalhista, um juiz na Bahia assentou a tese de que a reforma não se aplica aos processos já instruídos na data da entrada em vigor da Lei n 13.467/2017. Consultar: http://www.migalhas. com.br/Quentes/17,Ml270132,81042-JTBA+Reforma+trabalhista+nao+se+aplica+a+processos+ja+instruid os e https://jota.info/trabalho/sp-juiza-extingue-acoes-anteriores-a-reforma-trabalhista-22112017 Acesso em 29/11/2017, 21h44min. Por outro lado, há juízes afastando a aplicação da norma em razão de sua incompatibilidade com a Constituição, como um juiz do estado de São Paulo, que reverteu dispensa coletiva não procedida de negociação coletiva. Consultar: http://www.gazetadopovo.com.br/justica/juiz-nao-aplicareforma-trabalhista-e-reverte-demissao-em-massa-7cmtpjzot41cvaoepv619dow7 Acesso em 29/11/2017, 21h47min.

24 Consultar: The intercept Brasil, 17/11/2017. "Supermercado Mundial, o menor direito trabalhista total". Disponível em: https://theintercept.com/2017/11/17/mundial-greve-direitos-trabalhistas/. Acesso em 22/11/2017, 13h22min; e Esquerda Diário, 25/11/2017. "Empresa de telemarketing que pagar $R \$ 720$ e trabalhadores protestam em Salvador". Disponível em: http://www.esquerdadiario.com.br/Empresa-deTelemarketing-quer-pagar-R-720-e-trabalhadores-protestam-em-Salvador Acesso em 29/11/2017, 21 h50. 
Congresso Nacional, resvalou em grande medida numa tentativa de negociação com o próprio governo para a edição de uma Medida Provisória, posterior à aprovação da lei da Reforma, que supostamente corrigiria os "excessos", em especial a questão da contribuição sindical. A Medida Provisória n 808/2017, publicada em 14/11/2017, ficou longe de sanar excessos ou de resolver o problema da contribuição sindical, agravando, em verdade, alguns pontos do texto da reforma. Nesse cenário, o movimento sindical brasileiro, debilitado pela perda de sua fonte de financiamento e sensivelmente distanciado de suas bases trabalhadoras, retoma fôlego para tentar fazer frente à vindoura reforma previdenciária.

No caso francês, conforme demonstra Willemez (2017), embora os presidentes Hollande e Macron tenham logrado êxito na aprovação das reformas, houveram (e ainda há) resistências no meio sindical, jurídico e acadêmico. No âmbito sindical, segundo Landré (2017), o site cestlagreve.fr (que informa em tempo real todas as greves realizadas na França) registrou em 2016, 801 greves, sendo 110 greves nacionais. Dentre as greves nacionais realizadas, 13 foram greves gerais contra o projeto de Lei El Khomri. Já em 2017, verificamos a realização de 4 greves nacionais contra as ordonnances de Macron. Por fim, Willemez (2017) indica a formação de um grupo que reúne acadêmicos, jurídicos e sindicalistas, que tem promovido debates e outras ações contra o caráter liberalizante das reformas trabalhistas de Macron. Nesta mesma perspectiva, acadêmicos renomados como Alain Supiot e Emmanuel Dockès têm defendido posições públicas em favor do caráter protetor do direito do trabalho, tal como aborda Willemez (2017).

Em suma, constatamos que as reformas trabalhistas no Brasil e na França têm como objetivo uma reestruturação das relações de trabalho e desconstrução do sistema de direitos sociais. A racionalidade neoliberal vislumbra no desmonte do direito do trabalho um dos caminhos para pavimentar um sistema da relação entre capital e trabalho pautado pelo mercado e pela lógica individualizante e negocial. Nesse cenário, não parece difícil projetar que, considerado o processo desigual das forças envolvidas nas relações de trabalho e o contexto de desorganização coletiva dos trabalhadores, as reformas tendem a proporcionar o aumento da precarização social do trabalho e a perda de direitos. 


\section{Referências}

ARFI-ELKAÏM, Dahlia. Les principaux changements en droit du travail à compter du 1er janvier 2017. Disponível em: < https://www.jdbavocats.com/actualite-droit-social/206-lesprincipaux-changements-en-droit-du-travail-a-compter-du-1er-janvier-2017.html> . Acesso em: 17/11/2017.

BARRETO, T. da R. Trabalhadores informais e desempregados: a precarização como homogeneização "sui generis" na formação dos "sem emprego". Salvador: UFBA, 2005, 27op. Dissertação (Mestrado em Ciências Sociais) - Programa de Pós-Graduação em Ciências Sociais, Universidade Federal da Bahia, 2005.

BOURDIEU, Pierre. Contrafogos: táticas para enfrentar a invasão neoliberal. Tradução de Lucy Magalhães. Rio de Janeiro: Jorge Zahar Ed., 1998.

BRASIL. Constituição da Republica Federativa do Brasil 1988. Disponível em:< http:/l www.planalto.gov.br>. Acesso em: 30/07/2009.

CASTEL, Robert. As metamorfoses da questão social. Petrópolis: Vozes, 1998.

DARDOT, Pierre; LAVAL, Christian. A nova razão do mundo: ensaio sobre a sociedade neoliberal. São Paulo: Boitempo, 2016.

DELGADO, Gabriela Neves; AMORIM, Helder. Os limites constitucionais da terceirização. São Paulo: LTr, 2014.

DIEESE. Balanço das negociações dos reajustes salariais do $1^{\circ}$ semestre de 2016. Disponível em: http://www.dieese.org. br/balancodosreajustes/2016/ estPesq81balancoReajustes1semestre2016.pdf. Acesso em 20/11/2016, 15h30.

DRUCK, G. Globalização, reestruturação produtiva e movimento sindical. Caderno CRH, Salvador, n. 24/25, p. 21-40, jan./dez. 1996. <www.cadernocrh.ufba.br>.

DRUCK, G. Terceirização: (des)fordizando a fábrica - um estudo do complexo petroquímico de Camaçari. Campinas: Boitempo, 1999.

DRUCK, G. Precarização social do trabalho. In: IVO, A. B. L. (Coord). Dicionário temático desenvolvimento e questão social: 81 problemáticas contemporâneas. São Paulo: Annablume; Brasília: CNPq; Salvador: Fapesb, 2013, p. 373-380.

DRUCK, G. Precarização social do trabalho. In: IVO, A. B. L. (Coord). Dicionário temático desenvolvimento e questão social: 81 problemáticas contemporâneas. São Paulo: Annablume; Brasília: CNPq; Salvador: Fapesb, 2013, p. 373-380.

DRUCK, G; FRANCO, T. A perda da razão social do trabalho: terceirização e precarização do trabalho. São Paulo: Boitempo, 2007. 
DUTRA, Renata Queiroz. Entre a normatização estatal e a negociação coletiva: os desafios da proteção social ao trabalho. Revista do Tribunal Superior do Trabalho, v. 82, p. 272-301, 2017.

ESPINA, Álvaro. La reforma de la ley de trabajo en Francia: un caso de estúdio. Boletín económico de ICE, Información Comercial Española, ISSN 0214-8307, No 3076 (Del 1 al 30 de Junio 2016), 2016, págs. 15-36. Disponível em: < https://dialnet.unirioja.es/servlet/ articulo?codigo $=5767334>$. Acesso em: 01/08/2017.

EYDOUX, Anne; FRETEL, Anne. Réformes Du marche du travail - Des reformes contre l'emploi, jan. 2016. Disponível em: <http:// www.atterres.org>. Acesso em: 10/7/2016.

FILGUEIRAS, Vitor; CAVALCANTE, Sávio. Terceirização: um problema conceitual e político. Le Monde Diplomatique Brasil, p. 26 - 27, 05 jan. 2015.

GALVÃO, Andréia. Neoliberalismo e reforma trabalhista no Brasil. Campinas, 2003. Tese (Doutorado em Ciências Sociais). Departamento de Ciência Política do Instituto de Filosofia e Ciências Humanas da Universidade Estadual de Campinas (UNICAMP).

HARVEY, D. A condição pós-moderna. São Paulo: Loyola, 1992.

HIRATA, H; PRÉTECEILLE, E. Trabalho, exclusão e precarização socioeconômica: o debate das ciências sociais na França. Caderno CRH, Salvador, n. 37, p. 47-8o, jul./dez. 2002.

LANDRÉ, Marc. Malgré la loi travail, les Français ont moins fait grève en 2016. Paris, Le Figaro, 18/01/2017. Disponível em: < http://www.lefigaro.fr/social/2017/01/18/2001120170118ARTFIGo0018-malgre-la-loi-travail-les-francais-ont-moins-fait-greve-en-2016. php>. Acesso em: 07/07/2017.

LOURENÇO FILHO, Ricardo. Liberdade Sindical: percursos e desafios na história constitucional brasileira. 1º. ed. São Paulo: LTr, 2011.

MORIN, Marie-Laure. Derrière «le pragmatisme» des ordonnances, la perversion des droits fondamentaux. Paris, Droit ouvrier, ISSN 0222-4194, no. 831, 2017, p. 590-597.

OIT. World employment and social outlook 2015: The changing nature of jobs / International Labour Office. - Geneva: ILO, 2015.

SCHÖMANN, Isabelle. Réformes nationales du droit du travail en temps de crise : Bilan alarmant pour les droits fondamentaux et la démocratie en Europe., Revue Interventions économiques [En ligne], 52 | 2015, mis en ligne le 01 mars 2015, consulté le 18 décembre 2017. Dispoínvel em: < http://journals.openedition.org/interventionseconomiques/2437> . Acesso em: 17/06/2017.

SOUTO MAIOR, Jorge Luís. "A CLT é velha", publicado em 27/3/2017 no blog pessoal do autor. Disponível em: http://www.jorgesoutomaior.com/blog/i-a-clt-e-velha. Acesso em 23/5/2017, 18h12. 
WILLEMEZ, Laurent. Le travail dans son droit. Sociologie historique du droit du travail en France (1892-2017). Paris: L.G.D.J, 2017. (Collection: Contextes).

\begin{abstract}
In the context of a global rise of neoliberal rationality and the dismantling of rights and mechanisms of social security, this article aims to demonstrate how the labor reforms in Brazil and France are in accordance with this rationality, which intends to regulate working relations under the paradigm of private law and its commercial logic. This article is organized in three major parts: on the first, a discussion on neoliberalism and the deterioration of labor in Brazil and France will be made; on the second part, the recent changes in the Brazilian legislation will be analyzed, especially concerning the approval of the drafts bill which allows the outsourcing of core activities in the country (Law 13.429/2017), as well as Law 13.467/2017 (Labor Reform). Finally, the focus of the third part will be over the last two labor reforms implemented in 2016 and 2017 in France, allowing a reflection on the debate of the negotiated over the legislated, the flexibility of dismissals and on the limits of the working hours.

Keywords: Neoliberalism, Precariousness, Labor Law, Reforms, Brazil, France.
\end{abstract}

